\title{
Antimicrobial resistance among Brazilian Corynebacterium diphtheriae strains
}

\author{
Gabriela Andrade Pereira/1/ ${ }^{+}$, Fabrícia Pires Pimenta, Fátima Rejane Wink dos Santos², \\ Paulo Vieira Damasco3 ${ }^{3}$ Raphael Hirata Júnior, Ana Luíza Mattos-Guaraldi
}

\begin{abstract}
Disciplina de Microbiologia e Imunologia, Faculdade de Ciências Médicas, Universidade do Estado do Rio de Janeiro, Av. 28 de Setembro 87 - fundos, $3^{\circ}$ andar, 20551-030 Rio de Janeiro, RJ, Brasil 'Instituto de Microbiologia Professor Paulo de Góes, Universidade Federal do Rio de Janeiro, Rio de Janeiro, RJ, Brasil ${ }^{2}$ Serviço de Bacteriologia, Laboratório Central Noel Nutels, Rio de Janeiro, RJ, Brasil ${ }^{3}$ Departamento de Medicina Geral, Universidade Federal do Estado do Rio de Janeiro, Rio de Janeiro, RJ, Brasil
\end{abstract}

The increasing problems with multidrug resistance in relation to Corynebacterium, including C. diphtheriae, are examples of challenges confronting many countries. For this reason, Brazilian C. diphtheriae strains were evaluated by the E-Test for their susceptibility to nine antibacterial drugs used in therapy. Resistance (MIC $<0.002$; $0.38 \mu \mathrm{g} / \mathrm{ml}$ ) to penicillin $G$ was found in $14.8 \%$ of the strains tested. Although erythromycin $\left(M I C_{90} 0.75 \mu \mathrm{g} / \mathrm{ml}\right)$ and azithromycin $\left(M I C_{00} 0.064 \mu \mathrm{g} / \mathrm{ml}\right)$ were active against $\mathrm{C}$. diphtheriae in this study, $4.2 \%$ of the strains showed decreased susceptibility (MIC $1.0 \mu \mathrm{g} / \mathrm{ml}$ ) to erythromycin. Multiple resistance profiles were determined by the disk diffusion method using 31 antibiotics. Most C. diphtheriae strains (95.74\%) showed resistance to mupirocin, aztreonam, ceftazidime, and/or oxacillin, ampicillin, penicillin, tetracycline, clindamycin, lincomycin, and erythromycin. This study presents the antimicrobial susceptibility profiles of Brazilian $\mathrm{C}$. diphtheriae isolates. The data are of value to practitioners, and suggest that some concern exists regarding the use of penicillin.

Key words: Corynebacterium diphtheriae - multiresistance - penicillin - antibiotics

Penicillin and erythromycin have long been the drugs of choice for the eradication of toxin-producing strains of Corynebacterium diphtheriae from air passages. However, resistance to penicillin $\mathrm{G}$, oxacillin, erythromycin, and other drugs including rifampicin, tetracycline, and clindamycin used in therapy of $C$. diphtheriae infections have been reported (Formiga et al. 1971, Rockhill et al. 1982, Gruner et al. 1992, Maple et al. 1994, Patey et al. 1995, Gladin et al. 1999, Von Hunolstein et al. 2002). Resistance to ß-lactams should also be considered in systemic infections, since failure to eliminate $C$. diphtheriae in cases of endocarditis treated with penicillin have been reported. In the near future, antimicrobial susceptibility tests for both toxigenic and non-toxigenic $C$. diphtheriae strains may become practical. The increasing problems with multidrug resistance in $C$. diphtheriae are examples of challenges confronting tropical countries (Kneen et al. 1998, Gladin et al. 1999). In Brazil, as in much of the developing world, antibiotics are available freely without prescription and the emergence of multidrug-resistant $C$. diphtheriae is possibly another problem of concern. Thus, we report herein the susceptibility to antibacterial drugs used in therapy and the diverse multiresistance phenotypes of Brazilian C. diphtheriae strains.

Financial support: CNPq, CAPES, FAPERJ, SR2/UERJ, Programa de Núcleo de Excelência (PRONEX-MCT)

+Corresponding author: gabiap30@hotmail.com

Received 28 January 2008

Accepted 16 July 2008
Forty-seven (32 sucrose fermenting and 15 non sucrose fermenting; 42 toxigenic and 5 non-toxigenic) Brazilian C. diphtheriae strains isolated over a 21-year period (1981-2002) were examined. Phenotypic characteristics of microorganisms were confirmed by API Coryne System (bioMérieux, France) according to the manufacturer's instructions (Freney et al. 1991). Toxin production was evaluated by the Elek test (Efstratiou et al. 1998). C. diphtheriae subsp. mitis - CDC E-8392 and ATCC 27012 (toxigenic), ATCC 27010 (non-toxigenic), Staphylococcus aureus - ATCC 29213 ( $\beta$-lactamase positive), and ATCC 25923 ( $\beta$-lactamase negative) strains were used as controls.

Microorganisms were stored in $10 \%$ skim milk with $20 \%$ glycerol at $-70^{\circ} \mathrm{C}$ until further use. The procedures for susceptibility testing and the range of interpretative categories of susceptibility for each antimicrobial agent were similar to those recommended previously (Martínez-Martínez et al. 1995, Funke et al. 1996, Von Hunolstein et al. 2002). Antimicrobial susceptibility assays were determined by using Mueller Hinton base supplemented with $5 \%$ sheep blood and inoculums of $\sim 10^{5}$ $\mathrm{CFU} \backslash \mathrm{ml}$. Because of the absence of accepted breakpoints obtained by the disk diffusion method for coryneform bacteria CLSI (2006), guidelines for organisms other than Haemophilus spp. and Neisseria gonorrhoeae were used. The breakpoints for $S$. aureus were considered in the cases of penicillin, ampicillin, amoxicillin/clavulanic acid, oxacillin (Martínez-Martínez et al. 1995, Funke et al. 1996), methicillin, mupirocin (Salmenlinna et al. 2000), and linezolid (Goldstein et al. 1999). The E-Test (Biodisk, Solna, Sweden) was used to assay penicillin G, erythromycin, azithromycin, imipenem, tetracycline, gentamicin, clindamycin, rifampicin, and 
vancomycin in accordance with the guidelines provided by the manufacturers. Since the E-test previously presented an accordance of $94.9 \%$ with results obtained by the disk diffusion method to study antimicrobial susceptibly of corynebacteria (Martínez-Martínez et al. 1995), we used the disk diffusion test for determining the multiresistance profiles of $C$. diphtheriae strains for the following antibiotics (all from Oxoid, Hampshire, England): penicillin $\mathrm{G}(10 \mathrm{U})$, ampicillin $(10 \mu \mathrm{g})$, oxacillin $(1 \mu \mathrm{g})$, methicillin $(5 \mu \mathrm{g})$, amoxicillin/clavulanate $(20 / 10 \mu \mathrm{g})$, cephalothin $(30 \mu \mathrm{g})$, cefuroxime $(30 \mu \mathrm{g})$, cefotaxime $(30 \mu \mathrm{g})$, ceftriaxone $(30 \mu \mathrm{g})$, ceftazidime $(30 \mu \mathrm{g})$, cefoxitin $(30 \mu \mathrm{g})$, trimethoprim/sulfamethoxazole $(1.25 / 23.75 \mu \mathrm{g})$, gentamicin $(10 \mu \mathrm{g})$, amikacin $(30 \mu \mathrm{g})$, netilmicin $(30 \mu \mathrm{g})$, nalidixic acid $(30 \mu \mathrm{g})$, norfloxacin $(10 \mu \mathrm{g})$, perfloxacin $(10 \mu \mathrm{g})$, ofloxacin $(5 \mu \mathrm{g})$, ciprofloxacin $(5 \mu \mathrm{g})$, vancomycin $(30 \mu \mathrm{g})$, rifampicin $(5 \mu \mathrm{g})$, erythromycin $(15 \mu \mathrm{g})$, lincomycin $(2 \mu \mathrm{g})$, clindamycin $(2 \mu \mathrm{g})$, chloramphenicol $(30 \mu \mathrm{g})$, tetracycline $(30 \mu \mathrm{g})$, aztreonam $(30 \mu \mathrm{g})$, imipenem $(10 \mu \mathrm{g})$, mupirocin $(200 \mu \mathrm{g}$ and $5 \mu \mathrm{g})$, and linezolid $(30 \mu \mathrm{g})$. The $\beta$-lactamase production was evaluated by the nitrocefin disk method (Cefinase; Becton Dickinson Microbiology Systems, Cocksville, USA) (Riegel et al. 1994).

Antibiotics have been used to prevent further diphtheria toxin production and dissemination in symptomatic patients, clinical disease, spread from asymptomatic carriers, and colonization of close contacts. The presence of diphtheria bacilli resistant to drugs frequently used in the treatment of infections from different sources was noticed in some European countries (Von Hunolstein et al. 2002). Likewise, Brazilian C. diphtheriae strains exhibited resistance to different drugs used in antimicrobial therapy. The MIC range, $\mathrm{MIC}_{50}$ and $\mathrm{MIC}_{90}$ values determined by E-Test are shown in Table I. In our study, the evaluation of bacterial susceptibility to all drugs used in antimicrobial therapy exhibited $94.3 \%$ correlation among the results obtained by the disk diffusion method and E-Test, similar to data observed for corineforms (94.9\%) by Martínez-Martínez et al. (1995) (data

\section{TABLE I}

Antimicrobial susceptibilities of 47 Brazilian Corynebacterium diphtheriae strains evaluated by E-Test ${ }^{a}$

\begin{tabular}{llllc}
\hline & \multicolumn{4}{c}{ E-Test $\left(\mu \mathrm{g} \mathrm{ml}^{-1}\right)$} \\
\cline { 2 - 5 } Antimicrobial \\
\cline { 2 - 5 } agent & $\mathrm{MIC}_{50}$ & $\mathrm{MIC}_{90}$ & \multicolumn{1}{c}{ MIC Range } & $\begin{array}{c}\% \\
\text { Resistance }\end{array}$ \\
\hline Penicillin & 0.023 & 0.19 & $<0.002-0.38$ & 14.8 \\
Imipenem & 0.016 & 0.19 & $<0.002-1.5$ & 0 \\
Erythromycin & 0.094 & 0.75 & $<0.016-1.0$ & 4.2 \\
Azithromycin & 0.016 & 0.064 & $<0.016-1.0$ & 0 \\
Vancomycin & 0.50 & 0.75 & $<0.016-1.5$ & 0 \\
Clindamycin & 0.047 & 4 & $<0.016-32$ & 17 \\
Rifampicin & $<0.016$ & 0.016 & $<0.016-0.016$ & 0 \\
Gentamicin & 0.023 & 0.19 & $<0.016-0.75$ & 0 \\
Tetracycline & 0.094 & 6 & $<0.016-48$ & 12.8 \\
\hline
\end{tabular}

$a$ : E-Test was assayed in accordance with the guidelines provided by Martínez-Martínez et al. (1995). not shown). Even considering the breakpoints for $S$. $a u$ reus, we observed a decreased susceptibility to penicillin among $14.8 \%$ of the $C$. diphtheriae strains. Penicillin tolerance has been hypothesized to be a cause of treatment failure of $C$. diphtheriae infections (Patey et al. 1997, Von Hunolstein et al. 2002). All Brazilian strains tested were $\beta$-lactamase negative by the nitrocefin disk method. Penicillin represents the first antibiotic used to treat systemic $C$. diphtheriae infections, usually in combination with an aminoglycoside (Patey et al. 1997). A case of endocarditis in Rio de Janeiro proved to be fatal despite therapy with penicillin (Mattos-Guaraldi \& Formiga 1998). Presently, blood isolates showed susceptibility to all antimicrobial agents by E-test with MIC range from $<0.0016$ to 1.5 .

Besides diphtheria and/or prevention of infection through close contacts, macrolides have also been used in treatment of systemic $C$. diphtheriae infections. Azithromycin was described to have similar in vitro activity to erythromycin against $C$. diphtheriae (MIC 0.16; $0.3 \mu \mathrm{g} / \mathrm{ml}$ ) (Patey et al. 1997). Resistance to erythromycin has been described in different regions,

\section{TABLE II}

Antimicrobial multiresistance patterns presented by Brazilian Corynebacterium diphtheriae strains

\begin{tabular}{|c|c|c|}
\hline \multirow[b]{2}{*}{ Multiple resistance phenotypes } & \multicolumn{2}{|c|}{$\begin{array}{l}\text { Number of strains } \\
(\mathrm{n}=47)\end{array}$} \\
\hline & $\begin{array}{l}\text { Sucrose- } \\
\text { positive }\end{array}$ & $\begin{array}{l}\text { Sucrose- } \\
\text { negative }\end{array}$ \\
\hline MUP, ATM, CAZ, OXA, AMP, PEN, TET & 0 & 1 \\
\hline MUP, ATM, CAZ, OXA, AMP, PEN, LIN & 1 & 0 \\
\hline MUP, ATM, CAZ, OXA, AMP, CLI, ERY & 1 & 0 \\
\hline MUP, ATM, CAZ, OXA, PEN, CLI, TET & 0 & 1 \\
\hline MUP, ATM, CAZ, OXA, AMP, PEN ${ }^{a}$ & 1 & 2 \\
\hline MUP, ATM, CAZ,OXA, AMP, CLI & 1 & 0 \\
\hline MUP, ATM, CAZ,OXA, AMP, TET & 1 & 0 \\
\hline MUP, ATM, CAZ, OXA, PEN, CLI & 1 & 0 \\
\hline MUP, ATM, CAZ, OXA, PEN, TET & 1 & 0 \\
\hline MUP, ATM, CAZ, OXA, LIN, ERY & 1 & 0 \\
\hline MUP, ATM, OXA, AMP, PEN, TET & 0 & 1 \\
\hline MUP, ATM, CAZ, OXA, AMP ${ }^{b}$ & 7 & 5 \\
\hline MUP, ATM, CAZ, OXA, PEN & 1 & 1 \\
\hline MUP, ATM, CAZ, OXA, CLI & 1 & 1 \\
\hline MUP, ATM, CAZ, OXA, TET & 1 & 0 \\
\hline MUP, ATM, OXA, AMP, PEN & 0 & 1 \\
\hline MUP, ATM, CAZ, OXA & 7 & 2 \\
\hline MUP, ATM, CAZ, AMP & 3 & 0 \\
\hline MUP, ATM, CAZ, LIN & 1 & 0 \\
\hline MUP, ATM, OXA, AMP & 1 & 0 \\
\hline
\end{tabular}

Total \% 95.74

a: C. diphtheriae ATCC 27012 (toxigenic) and ATCC 27010 (non-toxigenic) strains used as controls; $b$ : Blood isolates from patients with endocarditis and $C$. diphtheriae subsp. mitis CDC E-8392 used as control; AMP: ampicillin; ATM: aztreonam; CAZ: ceftazidime; CLI: clindamycin; ERY: erythromycin; LIN: lincomycin; MUP: mupirocin; OXA: oxacillin; PEN: penicillin; TET: tetracycline. 
including industrialized and tropical countries (Vietnam) (Kneen et al. 1998, Gladin et al. 1999). Our results showed that erythromycin and azithromycin were active in vitro against $C$. diphtheriae isolates at different levels with $\mathrm{MIC}_{90}$ values of $0.75 \mu \mathrm{g} /$ $\mathrm{ml}$ and $0.064 \mu \mathrm{g} / \mathrm{ml}$, respectively. However, we observed a decreased susceptibility to erythromycin (4.2\%; MIC $1.0 \mu \mathrm{g} / \mathrm{ml})$ for two sucrose fermenting C. diphtheriae strains.

The presence of a plasmid among erythromycinresistant $\left(\mathrm{Em}^{\mathrm{r}}\right) C$. diphtheriae has been previously reported (Schiller et al. 1983). All microorganisms tested here were preliminarily screened for plasmids. Negative results (data not shown) confirmed earlier findings that plasmid carriage by $C$. diphtheriae is uncommon (Mattos-Guaraldi et al. 2000).

Brazilian C. diphtheriae strains were also observed to have $17 \%$ resistance to clindamycin. Data presented in Table II shows associated resistance to erythromycin and clindamycin (Patey et al. 1995, Gladin et al. 1999) for one $C$. diphtheriae strain. However, associated resistance to penicillin and erythromycin (Gladin et al. 1999) was not observed.

Resistance to tetracycline, although common in some countries, is very rare in others (Formiga et al. 1971, Patey et al. 1995, Gladin et al. 1999, Von Hunolstein et al. 2002). Tetracycline resistance was typical for isolates from Western Europe, Swiss intravenous drug users (Gruner et al. 1992), and hospitalized diphtheria patients in Jakarta, Indonesia (Rockhill et al. 1982). In previous studies, $C$. diphtheriae isolates from invasive infections were shown to be resistant to tetracycline and rifampicin (Patey et al. 1995, Von Hunolstein et al. 2002). Herein, Brazilian strains showed $12.8 \%$ resistance to tetracycline (MIC $16-48 \mu \mathrm{g} / \mathrm{ml}$ ) and $100 \%$ susceptibility to rifampicin. The invasive isolates were susceptible to tetracycline and rifampicin.

Bacteremia and endocarditis caused by both nontoxigenic and toxigenic $C$. diphtheriae strains have been reported with increased frequency (Mattos-Guaraldi \& Formiga 1998, Mishra et al. 2005). Only a few non-toxigenic strains were included in the study population. The toxigenicity seemed unrelated to drug resistance since resistance to different antimicrobial agents was also observed in all five non-toxigenic strains tested.

Since the 1970s, C. diphtheriae subsp. mitis of the sucrose fermenting biotype, uncommonly found in most industrialized countries, has been related with diphtheria outbreaks in different regions of Brazil (Mattos-Guaraldi et al. 2003). Here, multiple resistance phenotypes were observed among $C$. diphtheriae strains of both sucrose fermenting and non sucrose fermenting biotypes (Table II). Nearly all strains $(95.74 \%)$ were resistant to between four and seven drugs tested. Four isolates $(8.5 \%)$ had multiple resistance to seven drugs: mupirocin, penicillin and/or ampicillin, oxacillin, ceftazidime, aztreonam, tetracycline and/or lincomycin, clindamycin, erythromycin. Microorganisms were all susceptible to methicillin, amoxicillin/clavulanic acid, imipenem, and cephalosporines tested, except ceftazidime; and to linezolid, azithromycin, vancomycin, rifampicin, gentami- cin, amikacin, netilmicin, chloramphenicol, trimethop$\mathrm{rim} / \mathrm{sulphamethoxazole,} \mathrm{and} \mathrm{quinolones} \mathrm{evaluated} \mathrm{in} \mathrm{this}$ study, except nalidixic acid. In contrast to data previously collected in St. Petersburg, Russian Federation, where $2.3 \%$ of the isolates showed multiple resistance to eight drugs (Gladin et al. 1999), multiresistant Brazilian isolates showed susceptibility to chloramphenicol and trimethoprim. Present data were also different from those previously observed in Vietnam (Kneen et al. 1998), where $20 \%$ of C. diphtheriae isolates were found multiresistant to drugs, but $27 \%$ presented increased resistance to erythromycin and $100 \%$ susceptibility to penicillin.

Only two strains did not show multiresistance to the antimicrobial agents tested. All strains, except one, showed resistance to oxacillin and/or ampicillin. However, 11 (5 sucrose-positive; 6 sucrose-negative) strains showed resistance to penicillin, indicating that resistance to penicillin was independent of sucrose fermentation. We did not observe microorganisms concomitantly resistant to penicillin and erythromycin. As shown in Table II, the expression of multiresistance phenotypes was independent of sucrose fermenting biotypes.

The expression of mupirocin resistance warrants further investigation of $C$. diphtheriae strains from different geographical areas. Data lead to the hypothesis that the control of the spread of methicillin-resistant staphylococci (Talon et al. 1995) may favor human colonization by diphtheria bacilli, including toxigenic and/or invasive strains in a nosocomial environment (Mattos-Guaraldi et al. 2003). Present data emphasize the need for a continuous survey of antibiotic susceptibility of $C$. diphtheriae, especially in developing countries where diphtheria is endemic and invasive infections may occur.

\section{REFERENCES}

CLSI - Clinical and Laboratory Standards Institute 2006. Antimicrobial susceptibility testing of fastidious or infrequently isolated organisms. Approved Standard Document M45-A, Wayne, p. 18-19.

Efstratiou A, Engler KH, Dawes CS, Sesardic D 1998. Comparison of phenotypic and genotypic methods for detection of diphtheria toxin among isolates of pathogenic corynebacteria. J Clin Microbiol 36: 3173-3177.

Formiga LCD, Peres da Silva AC, Pinheiro AR, Assumpção RL, Silveira MH, Serpa CEV, Suassuna I 1971. Estudo in vitro sobre a sensibilidade do Corynebacterium diphtheriae a treze antibióticos. Braz J Microbiol 2: 117-122.

Freney J, Duperron MT, Courtier C, Hansen W, Allard F, Boeufgras JM, Monget D, Fleurette J 1991. Evaluation of API Coryne in comparison with conventional methods for identifying coryneform bacteria. J Clin Microbiol 29: 38-41.

Funke G, Punter V, von Graevenitz A 1996. Antimicrobial susceptibility patterns of recently established coryneform bacteria. Antimicrob Agents Chemother 40: 2874-2878.

Gladin DP, Koslova NS, Zaitseva TK, Cherednichenko, AS, Khaval AS 1999. Sensitivity of Corynebacterium diphtheriae isolated in Saint Petersburg to antibacterial drugs. Antibiot Khimioter 44: 17-21.

Goldstein EJC, Citron DM, Merriam CV, Warren YA, Tyrell KL, Fernandez HT 1999. Linezolid activity compared to selected macrolides and other agents against aerobic and anaerobic pathogens isolated from soft tissue bite infections in humans. Antimicrob Agents Chemother 43: 1469-1474. 
Gruner E, Zúber PLF, Martinetti Luchini G, von Graevenitz A, Altweeg M 1992. A cluster of nontoxigenic Corynebacterium diphtheriae infection among Swiss intravenous drugs abusers. Med Microbiol Lett 1: 160-167.

Kneen R, Pham NG, Solomon T, Tran TM, Nguyen TT, Tran BL, Wain J, Day NP, Tran TH, Parry CM, White NJ 1998. Penicillin vs. erythromycin in the treatment of diphtheria. Clin Infect Dis 27: 845-850.

Maple PA, Efstratiou A, Tseneva G, Rikunshin Y, Deshevoi S, Jackhola M, Vuopio-Varkila J, George RC 1994. The in-vitro susceptibilities of toxinogenic strains of Corynebacterium diphtheriae isolated in northwestern Russia and surrounding areas to ten antibiotics. J Antimicrob Chemother 34: 1037-1040.

Martínez-Martínez L, Ortega MC, Suárez AI 1995. Comparison of ETest with broth microdilution and disk diffusion for susceptibility testing of coryneform bacteria. J Clin Microbiol 33: 1318-1321.

Mattos-Guaraldi AL, Formiga LCD 1998. Bacteriological properties of a sucrose fermenting Corynebacterium diphtheriae strain isolated from a case of endocarditis. Curr Microbiol 37: 156-158.

Mattos-Guaraldi AL, Formiga LCD, Pereira GA 2000. Cell surface components and adhesion in Corynebacterium diphtheriae. Microbes Infect 2: 1507-1512.

Mattos-Guaraldi AL, Moreira LO, Damasco PV, Hirata Jr R 2003. Diphtheria remains a threat to health in developing world - An overview. Mem Inst Oswaldo Cruz 98: 987-993.

Mishra B, Dignan RJ, Hughes CF, Hendel N 2005. Corynebacterium diphtheriae endocarditis -surgery for some but not all. Asian Cardiovasc Thorac Ann 13: 119-126.

Patey O, Bimet F, Emond JP, Estrangin E, Riegel PH, Halioua B, Del- lion S, Kiredjian M 1995. Antibiotic susceptibilities of 38 nontoxigenic strains of Corynebacterium diphtheriae. J Antimicrob Chemother 36: 1108-1110.

Patey O, Bimet F, Riegel P, Halioua B, Emond JP, Estrangin E, Dellion S, Alonso JM, Kiredjian M, Dublanchet A, Lafaix C 1997. Clinical and molecular study of Corynebacterium diphtheriae systemic infections in France. J Clin Microbiol 35: 441-445.

Riegel P, Briel D, Prévost G, Jehl F, Monteil H 1994. Genomic diversity among Corynebacterium jeikeium strains and comparison with biochemical characteristics and antimicrobial susceptibilities. J Clin Microbiol 32: 1860-1865.

Rockhill RC, Sumarmo HH, Siregar SP, Muslihun B 1982. Tetracycline resistance of Corynebacterium diphtheriae isolated from Diphtheria patients in Jakarta, Indonesia. Antimicrob Agents Chemother 21: 842-843.

Salmenlinna S, Lyytikainen O, Kotilainen P, Scotford R, Siren E, Vuopio-Varkila J 2000. Molecular epidemiology of methicillinresistant Staphylococcus aureus in Finland. Eur J Clin Microbiol Infect Dis 19: 101-107.

Schiller J, Groman N, Coyle M 1983. Plasmids in Corynebacterium diphtheriae mediating erythromycin resistance. Antimicrob Agents Chemother 18: 814-821.

Talon D, Rouget C, Cailleaux V, Bailly P, Thouverez M, Barale F, Michel-Briandy Y 1995. Nasal carriage of Staphylococcus aureus and cross-contamination in a surgical intensive care unit: efficacy of mupirocin ointment. J Hosp Infect 30: 39-49.

Von Hunolstein C, Scopetii F, Efstratiou A, Engler K 2002. Penicillin tolerance amongst non-toxigenic Corynebacterium diphtheriae isolated from cases of pharingitis. J Antimicrob Chemother 50: 125-128. 